\title{
Effects of nutrient addition on algae pigments during the early stages of phytoplankton bloom
}

\author{
Li Yu ${ }^{1,2,3^{*}}$, Weihua $\mathrm{Li}^{1}$, Rong Wang ${ }^{1}$, Qiang Yuan ${ }^{1}$ \\ ${ }^{1}$ School of Environment and Energy Engineering, Anhui Jianzhu University, Heifei 230601, China. \\ ${ }^{2}$ Key Laboratory of Water Pollution Control and Wastewater Reuse, Anhui Jianzhu University, Hefei 230601, China \\ ${ }^{3}$ Key Laboratory of Huizhou Architecture in Anhui Province, Heifei 230601, China.
}

\begin{abstract}
To clarify the effects of nutrient addition on algal growth during the early stages of phytoplankton bloom, an microcosm experiment was conducted in early spring; it included two groups of in situ samples: sediment plus lake water $(\mathrm{S}+\mathrm{W})$, representing the nominal "control", and sediment plus 50\% BG11 medium and $50 \%$ lake water $(\mathrm{S}+\mathrm{BW})$, representing the treatment of nutrient addition. The results demonstrated the recruitment biomass of non-cyanobacteria in the treatment group was about $46.7 \%$ of that in the control group, and the recruitment biomass of cyanobacteria in the treatment group was approximately 5 times than that in the control. After recruitment, nutrient addition generated remarkable stimulation of the growth of all algae, especially cyanobacteria. The results suggested that the stimulation by nutrient addition of algal growth after recruitment may be responsible for the occurrence of phytoplankton blooms, and the more pronounced promotion of cyanobacteria than non-cyanobacteria was explainable for the strengthening of the dominance of cyanobacteria during eutrophication.
\end{abstract}

\section{Introduction}

Eutrophication is becoming a serious environmental problem in freshwater ecosystems. Excessive nutrients in water leaded to frequent occurrence of cyanobacteria bloom, which threatened the safety of water environment (Smith et al., 1999). In temperate areas, the seasonal cycling of algae is divided into different stages based on their growth characteristics (Reynolds et al., 1981). Kong and Gao (2005) proposed "the theory of four stages" for the formation of phytoplankton blooms, in which algal recruitment is followed by massive growth and propagation of algae prior to the occurrence of a phytoplankton bloom. Thus, the effect of nutrient increase on algal growth during the early stages was vital in revealing the features of summer blooms. However, previous studies mainly focused on the relationship between nutrient levels and the occurrence of a phytoplankton bloom (Paerl et al., 2011), and few were involved in the effect of nutrient addition on algal growth during the early stages.

Lake Taihu, is the third largest freshwater lake in China $\left(119^{\circ} 54^{\prime}-120^{\circ} 36^{\prime} \mathrm{N}, 30^{\circ} 56^{\prime}-31^{\circ} 33^{\prime} \mathrm{E}\right.$; surface area: $2338 \mathrm{~km}^{2}$ ). It is an important resource for drinking, fisheries, irrigation and recreation (Song et al., 2007). In recent years, the occurrence of cyanobacterial blooms in warm seasons has increased in frequency and intensity, which damages the function of the lake as a drinking water

Email of all the authors: yuli514605@163.com;

liweihua9@126.com;969430819@qq.com; ronger@ahjzu.edu.cn

*Corresponding Author: Li Yu; email: yuli514605@163.com;

phone: 0551-63828252; fax: 0551-63828026. supply and poses a public health risk (Xie et al., 2008). Therefore, it is necessary to understand the relationship between nutrient concentrations and algal blooms in this large lake system, especially during the pre-algal recruitment phase; a better understanding of this relationship is essential for the prevention and control of phytoplankton blooms.

The purpose of this study is to investigate the effects of elevated nutrient concentrations on algae recruitment and growth following recruitment. To accomplish this, we simulated a recruitment experiment in a laboratory, algae were inoculated in two treatment groups and cultivated from overwintering the occurrence of a phytoplankton bloom. Changes in pigments of the algae were monitored during the algae's growth.

\section{Materials and methods}

\subsection{Experimental setup}

In order to simulate algal recruitment, the in situ sediment and lake water in the western regions of the lake were sampled in early spring when the average water temperature was approximately $6^{\circ} \mathrm{C}$. Sediment (the upper 0-2 cm) was collected using a polyethylene corer (diam. $10 \mathrm{~cm})$, and lake water (0-2 $\mathrm{m}$ depth) was obtained using a plastic column sampler (diam. $10 \mathrm{~cm})$. All samples were stored in a constant temperature chest and immediately transported to the laboratory. 
A microcosm experiment was conducted in the laboratory. Two treatments were set up: control $(\mathrm{S}+\mathrm{W})$ and nutrient addition $(\mathrm{S}+\mathrm{BW})$; each treatment was triplicated. All 36 flasks were randomly divided into these two groups. The nominal control group $(\mathrm{S}+\mathrm{W})$ had $25 \pm 0.01 \mathrm{~g}$ (wet weight) homogenised sediment and $240 \mathrm{~mL}$ lake water, reflecting the typical situation for algal growth under field conditions. The treatment with added nutrients (S+BW) had $25 \pm 0.01 \mathrm{~g}$ sediment, $120 \mathrm{~mL}$ BG11 growth medium (Rippka et al., 1979), and $120 \mathrm{~mL}$ lake water, reflecting algal growth under nutrient addition. At the beginning, all flasks were stored in darkness at $6{ }^{\circ} \mathrm{C}$ for 5 days of adaptation. The cultivation condition was set to $30 \mu \mathrm{mol}$ photons $\mathrm{m}^{-2} \mathrm{~s}^{-1}$ light intensity with a cold-white fluorescent lamp on a 12:12 L:D cycle with an initial temperature of $6{ }^{\circ} \mathrm{C}$. Subsequently, the temperature in the chamber increased at a rate of $1{ }^{\circ} \mathrm{C}$ every 5 days. On the final day of the series of temperature treatments, $6,9,12$, 15,18 , and $21{ }^{\circ} \mathrm{C}, 6$ flasks ( 3 flasks per treatment) were taken out, and the water column and sediment were carefully separated and sampled.

\subsection{Nutrient determination}

Total nitrogen (TN) and total phosphorous (TP) were measured using a combined persulfate digestion followed by spectrophotometric analysis, as described for soluble reactive phosphorus and nitrate according to "Chinese Standard Methods for Lake Eutrophication Survey" (Jin and Tu, 1990).

\subsection{Pigments measurement}

For determination of phycocyanin (PC), $100 \mathrm{~mL}$ water sample was filtered using GF/C (pore size $1.2 \mu \mathrm{m}$, Whatman, UK), the filtration membrane was homogenised with $0.05 \mathrm{~mol} \mathrm{~L}^{-1}$ Tris- $\mathrm{HCl}$ buffer at $\mathrm{pH} 7.0$ and then conducted by colourimetry with a fluorescence spectrophotometer (RF-5301PC, Sahimadzu, Japan). For determination of chlorophyll a (Chl a) and chlorophyll b $(\mathrm{Chl} b)$, the procedures were the same as above except that Tris-HCl buffer was replaced with $90 \%$ acetone (v/v) at $\mathrm{pH}$ 7.0. Based on the algae species identified in Lake
Taihu, the concentrations of $\mathrm{Chl} \mathrm{a}, \mathrm{Chl} \mathrm{b}$, and $\mathrm{PC}$ were indicative of the biomass of total algae, non-cyanobacteria, and cyanobacteria, respectively. The temperature of the water when the first significant increase of pigment across treatments appeared was considered to be the initiation temperature for algal recruitment (Cao et al., 2008).

\subsection{Statistical analysis}

Data were collected in triplicates and presented as mean \pm standard deviation (SD). The dynamics of algal growth across treatments was analysed using a general linear model (univariate GLM; SPSS 13.3) with the temperature and treatment being fixed factors. Other analyses were directly compared with the control via t-tests. Differences were considered significant when $p<0.05$.

\section{Results}

\subsection{Algal recruitment in cultivation water}

The changes in the concentration of pigments in the water column are shown in Fig. 1,2,3. The recruitment of total algae was initiated at $12{ }^{\circ} \mathrm{C}$. Post-recruitment, from $15^{\circ} \mathrm{C}$ to $21{ }^{\circ} \mathrm{C}$, the average biomass of total algae was $84.08 \mu \mathrm{g}$ $\mathrm{L}^{-1}$ in $\mathrm{S}+\mathrm{BW}$, which was significantly higher than the $11.97 \mu \mathrm{g} \mathrm{L}^{-1}$ in the control $(\mathrm{S}+\mathrm{W})(p<0.05$, t-tests) (Fig. 1a).

The recruitment of non-cyanobacteria was also initiated at $12{ }^{\circ} \mathrm{C}$. At $12{ }^{\circ} \mathrm{C}$, the recruitment biomass of non-cyanobacteria in $\mathrm{S}+\mathrm{W}\left(9.16 \pm 0.28 \mu \mathrm{g} \mathrm{L}^{-1}\right)$ was approximately twice as high as that in S+BW $(4.28 \pm 0.23$ $\mu \mathrm{g} \mathrm{L}-1)(p<0.05$, t-tests) (Fig. $1 b)$. Post recruitment, from $15^{\circ} \mathrm{C}$ to $21{ }^{\circ} \mathrm{C}$, the average biomass of non-cyanobacteria in $\mathrm{S}+\mathrm{BW}$ was higher than that in $\mathrm{S}+\mathrm{W}$.

The recruitment of cyanobacteria was initiated at $15^{\circ} \mathrm{C}$. At $15^{\circ} \mathrm{C}$, the recruitment biomass of cyanobacteria in $\mathrm{S}+\mathrm{BW}\left(13.95 \pm 0.57 \mu \mathrm{g} \mathrm{L}^{-1}\right)$ was five times as high as in $\mathrm{S}+\mathrm{W}\left(2.75 \pm 0.16 \mu \mathrm{g} \mathrm{L}^{-1}\right)$ (Fig. 1c). Post recruitment, from $18{ }^{\circ} \mathrm{C}$ to $21{ }^{\circ} \mathrm{C}$, the average biomass of cyanobacteria in $\mathrm{S}+\mathrm{BW}$ was significantly higher than in $\mathrm{S}+\mathrm{W}(p<0.05$, ttests) (Fig. 1c).
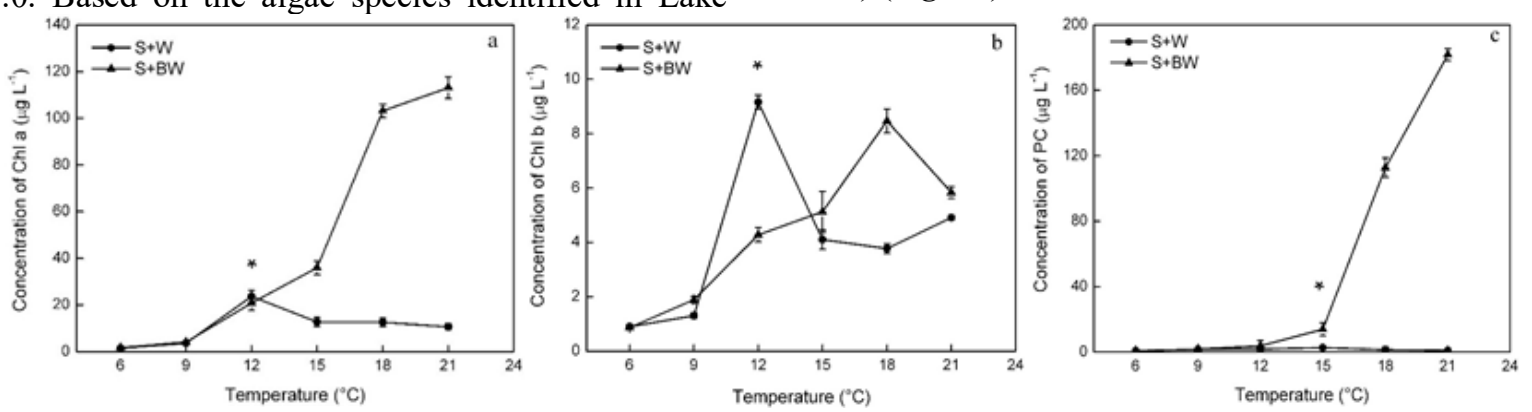

Fig. 1. The changes of the concentration of Chl a (a), Chl b (b), PC (c)in cultivation water. Data are the averages with SD (bars) of triplicates; * represents the first significant increment.

\subsection{Nutrient concentrations}

Changes in the concentrations of TN and TP are shown in Table 1. During the entire process from $6{ }^{\circ} \mathrm{C}$ to $21^{\circ} \mathrm{C}$, no significant changes were detected in the sediment between the control $(\mathrm{S}+\mathrm{W})$ and the treatment with nutrient addition $(\mathrm{S}+\mathrm{BW})$; in contrast, in the water column, TN and TP in the treatment with added nutrients were significantly higher than in the control at $21^{\circ} \mathrm{C}$. 
Table 1. Concentrations of TN and TP in sediment and overlying water during recruitment. Data are the averages with SD (enclosed in brackets) of triplicates.

\begin{tabular}{cccccccc}
\hline \multirow{2}{*}{ Treatment } & \multicolumn{9}{c}{ Sediment $\left(\mathrm{mg} \mathrm{g}^{-1}\right)$} & \multicolumn{2}{c}{$\begin{array}{c}\text { Overlying } \\
\text { Water }\left(\mathrm{mg} \mathrm{L}^{-1}\right)\end{array}$} \\
\cline { 2 - 7 } & $6^{\circ} \mathrm{C}$ & $9{ }^{\circ} \mathrm{C}$ & $12^{\circ} \mathrm{C}$ & $15^{\circ} \mathrm{C}$ & $18{ }^{\circ} \mathrm{C}$ & $21{ }^{\circ} \mathrm{C}$ & $21{ }^{\circ} \mathrm{C}$ \\
\hline S+W & $2.16(0.29)$ & $1.61(0.25)$ & $1.58(0.23)$ & $1.56(0.21)$ & $1.76(0.30)$ & $1.56(0.23)$ & $0.58(0.04)$ \\
S+BW & $1.94(0.29)$ & $1.76(0.27)$ & $2.00(0.32)$ & $1.74(0.25)$ & $1.88(0.27)$ & $1.85(0.26)$ & $108.01(0.17)$ \\
\hline
\end{tabular}

\section{Discussion}

The results from the present study demonstrated that nutrient addition increased the recruitment biomass of cyanobacteria and concurrently stimulated the subsequent growth of both cyanobacteria and non-cyanobacteria. However, the data of PC concentration showed that the stimulation of cyanobacteria was more pronounced than non-cyanobacteria, and the dominance of cyanobacteria was strengthened as temperature increased (Fig. 1b, c). Furthermore, under nutrient addition, the danger of a cyanobacterial bloom would be aggravated due to the host preferences of toxic populations of Microcystis (Davis et al., 2009). Therefore, it is predicted that more severe and harmful cyanobacterial blooms will break out if the eutrophication in Lake Taihu can not be effectively controlled.

The effect of nutrient addition on algal recruitment varied among algal species; it promoted the growth of cyanobacteria but not non-cyanobacteria. This may be related to species specific features during overwintering. During overwintering, non-cyanobacteria existed as resting spores (Anderson, 1976), while cyanobacteria existed as vegetative cells (Fallon and Brock, 1981), which accounts for the differences of stored energy in algae upon recruitment when they encountered favourable environmental conditions (Wu et al., 2008). As a result, compared with non-cyanobacteria, the recruitment of cyanobacteria exhibited more reliance on the supply of external nutrients and was greatly stimulated by nutrient addition.

Post recruitment, nutrient addition promoted the growth of both cyanobacteria and non-cyanobacteria. Under constant conditions, the competitive ability of algae determines the extent of their growth. Cyanobacteria can undoubtedly benefit from this competition due to higher growth rates (Davis et al., 2009) and a greater specific growth rate (Wu et al., 2008) than non-cyanobacteria. Therefore, though the growth of both cyanobacteria and non-cyanobacteria was promoted, a much greater increase in cyanobacteria was detected. The proportion of cyanobacteria exceeded that of non-cyanobacteria until the occurrence of a phytoplankton bloom, thus further strengthening the dominance of cyanobacteria.

\section{Conclusions}

The results demonstrated that the recruitment biomass of non-cyanobacteria and cyanobacteria decreased by $46.7 \%$ and increased 5 times, respectively. The experiment indicated that it promoted cyanobacteria more than non- cyanobacteria and concurrently stimulated the subsequent growth of both cyanobacteria and non-cyanobacteria, especially cyanobacteria, which further strengthened the dominance of cyanobacteria during eutrophication. This knowledge will play an important role in the prevention and control of phytoplankton blooms.

\section{Acknowledgments}

This work was supported by the National Natural Science Foundation of China (41601203), The Docotor Fund Project for Talents of Anhui Jianzhu University (2019QDZ10); Anhui Key project of research and development plan (1704a0902006) and Major science and technology project of Anhui Province (17030801028); the Science and Technology Major projects of Anhui Province (18030801106,)

\section{References}

1. Anderson O.R., 1976. Respiration and photosynthesis during resting cell formation in Amphora coffeaeformis (Ag.) Kütz. Limnol. Oceanogr., 21, 452-456.

2. Cao H.S., Tao Y., Kong F.X. and Yang Z., 2008. Relationship between temperature and cyanobacterial recruitment from sediments in laboratory and field studies. J. Freshwater Ecol., 23, 405-412.

3. Davis T.W., Berry D.L., Boyer G.L. and Gobler C.J., 2009. The effects of temperature and nutrients on the growth and dynamics of toxic and non-toxic strains of Microcystis during cyanobacteria blooms. Harmful Algae, 8, 715-725.

4. Fallon R.D. and Brock T.D., 1981. Overwintering of Microcystis in Lake Mendota. Freshwater Biol., 11, 217-226.

5. Jin X. and Tu Q., 1990. The standard methods for observation and analysis in Lake Eutrophication, 2nd ed, Chinese Environmental Science Press. Beijing, 240 pp (in Chinese).

6. Kong F. and Gao G., 2005. Hypothesis on cyanobacteria bloom-forming mechanism in large shallow lakes, allelopathy (in Chinese). Acta. Ecol. Sin., 25, 589-595.

7. Paerl H.W., Xu H., McCarthy M.J., Zhu G., Qin B., Lie Y. and Gardner W.S., 2011. Controlling harmful cyanobacterial blooms in a hyper-eutrophic lake (Lake Taihu, China): The need for a dual nutrient (N\& P) management strategy. Water Res., 45, 19731983. 
8. Reynolds C.S., Jaworsky G.H.M., Cmiech H.A. and Leedale G.F., 1981. On the annual cycle of the bluegreen alga Microcystis aeruginosa Kütz. Emend. Elenkin. Philos. T. R. Soc. B., 293, 419-77.

9. Rippka R., Deruelles J., Waterbury J.B., Herdman M. and Stanier R.Y., 1979. Generic assignments, strain histories and properties of pure cultures of cyanobacteria. J. Gen. Microb., 111, 1-61.

10. Smith V.H., Tilman G.D. and Nekola J.C., 1999. Eutrophication: impacts of excess of nutrient addition on freshwater, marine, and terrestrial ecosystems. Environ. Pollut., 100, 179-196.

11. Song L.R., Chen, W., Peng L., Wan N., Gan N.Q., and Zhang X.M., 2007.Distribution and bioaccumulation of microcystins in water columns: a systematic investigation into the environmental fate and the risks associated with microcystins in Meiliang Bay, Lake Taihu. Water Res. 41, 2853-2864.

12. Wu Z., Song L. and Li R., 2008. Different tolerances and responses to low temperature and darkness between waterbloom forming cyanobacterium Microcystis and a green alga Scenedesmus. Hydrobiologia, 596, 47-55.

13. Xie P., 2008. Historical development of cyanobacteria with bloom disaster in Lake Taihu. Science Press, Beijing. 